\title{
New Genus, Coprococcus, Twelve New Species, and Emended Descriptions of Four Previously Described Species of Bacteria from Human Feces
}

\author{
LILLIAN V. HOLDEMAN and W. E. C. MOORE \\ Anaerobe Laboratory, Virginia Polytechnic Institute and State University, Blacksburg, Virginia 24061
}

\begin{abstract}
A new genus of anaerobic cocci, Coprococcus, and 12 new species of anaerobes, Coprococcus eutactus, $C$. catus, $C$. comes, Ruminococćus callidus, $R$. torques, Streptococcus hansenii, Bacteroides eggerthii, Eubacterium eligens, E. formicigenerans, $E$. hallii, Lactobacillus rogosae, and Clostridium nexile, are described. Emended descriptions and proposed neotype strains for Streptococcus constellatus (Prévot) comb. nov., S. morbillorum (Prévot) comb. nov., $S$. intermedius Prévot, and Eubacterium bijorme (Eggerth) Prévot are presented.
\end{abstract}

During quantitative and qualitative studies of the human fecal flora, a large number of previously undescribed bacterial species was encountered as predominant members of the flora. Of these species, those for which we have nine or more isolates from six or more persons are described here. In addition, the taxonomic position of some species of cocci is discussed, and for Eubacterium biforme (Eggerth) Prévot, an emended description is presented and a neotype strain is designated.

A discussion of the incidence of these species as compared with other kinds of organisms of the intestinal flora is published elsewhere (8).

\section{MATERIALS AND METHODS}

The organisms described in this report were isolated and characterized according to anaerobic tube culture methods and procedures previously described $(5,8$, 18).

Blood agar plates (BAP) were prepared aerobically on the day of use from brain heart infusion agar (BHIA; Difco) dehydrated base with $0.5 \%$ yeast extract, vitamin $\mathrm{K}$-hemin solution (5), and $5 \%$ sheep blood added.

Egg yolk agar plates (EYA) were stored in an anaerobe jar if not used the day of preparation and were streaked within 5 days of the preparation date. If growth did not occur, organisms were retested by using freshly prepared medium.

Plates were incubated in vented GasPak jars in an atmosphere of $90 \%$ hydrogen- $10 \% \mathrm{CO}_{2}$ after three series of partial evacuation and filling with the gas mixture.

Production of $\mathrm{H}_{2} \mathrm{~S}$ was determined in prereduced SIM medium (BBL).
The moles percent guanine plus cytosine $(\mathrm{G}+\mathrm{C})$ content of the deoxyribonucleic acid (DNA) preparations was determined by the thermal melting point $\left(T_{m}\right)$ method (7) by using an automatic recording spectrophotometer (Gilford Instrument Laboratories). DNA from Escherichia coli B was included in each set of analyses as a standard.

\section{RESULTS AND DISCUSSION}

\section{Anaerobic Cocci}

Coprococcus gen. nov., and new species of the genus Coprococcus

Many strains of the anaerobic, gram-positive cocci isolated in this study did not have characteristics that would permit their inclusion in any of the described genera. These strains do not belong to any presently described genera in the family Peptococcaceae Rogosa (14). They are unlike ruminococci because they produce butyric acid. They do not occur in packets, so they are not members of Sarcina. They are unlike Peptococcus and Peptostreptococcus because carbohydrates appear to be the main energy source, whereas peptones are used as a nitrogen source.

For this group of organisms we propose the name Coprococcus gen. nov. (Co'pro.coc'cus Gr. n. copro feces; Gr. n. coccus berry; M.L. masc. n. Coprococcus fecal coccus). Coprococcus includes those gram-positive, anaerobic cocci that actively ferment carbohydrates, producing butyric and acetic acids with formic or propionic and/or lactic acids. Fermentable carbohydrates are either required or are highly stimulatory for growth and continued subculture. The $\mathrm{G}+\mathrm{C}$ content of the DNA of the 
strains tested is 39 to $42 \mathrm{~mol} \%$. The type species is $C$. eutactus sp. nov.

Because the coprococci are gram-positive, anaerobic cocci, they are classified in the family Peptococcaceae in the order Eubacteriales. Characteristics useful in differentiating Coprococcus from other genera in the family are given in Table 1. Descriptions of three new species of Coprococcus are given in Table 2 and in the following discussion.

(i) Coprococcus eutactus sp. nov. (Gr. adj. eu.tac'tus orderly, well disciplined [referring to the uniform reactions of the different strains].) Obligately anaerobic, nonmotile, gram-positive cocci which usually occur in pairs. Cells may decolorize easily, particularly in media containing a fermentable carbohydrate. Cells were usually round, and 0.7 to $1.3 \mu \mathrm{m}$ in diameter; they could be slightly elongate in peptone-yeast extract (PY)-glucose cultures (Fig. 1).

Colonies. After incubation for 5 days in rumen fluid-glucose-cellobiose agar (RGCA) roll tubes, colonies were 0.5 to $2 \mathrm{~mm}$ in diameter, white or tan, lenticular, and translucent; the centers of the colonies were occasionally granular or opaque.

On anaerobic BAP incubated for 2 days, surface colonies of the type strain were punctiform, circular, entire, convex, translucent, whitish, smooth, shiny, and without hemolytic activity. There was no growth on BAP incubated in a candle jar or in an aerobic atmosphere.

Cultural characteristics. There was poor or no growth in PY broth without fermentable carbohydrate. PY-glucose cultures had abundant growth and a smooth (occasionally ropy) sediment; there usually was a slight to moderate turbidity; after incubation for 5 days the $\mathrm{pH}$ was 4.7 to 5.0 .

Growth occurred equally well at 37 and 45 $C$; growth was poor to moderate at 25 and 30 C.

Biochemical reactions. The characteristics of 59 isolates of this species are given in Table 2. In addition, the type strain and five other strains tested fermented dextrin, reduced neutral red, and produced acetylmethylcarbinol (AMC). The six strains tested did not ferment adonitol, glycerol, inulin, or sorbose and therefore grow poorly, if at all, in PY media containing these substrates. No reaction was produced on EYA by five strains; one strain did not grow on the surface of EYA incubated anaerobically. No ammonia was detected from cultures in chopped meat, PY, PY-glucose, or arginine medium. Hippurate was not hydrolyzed, and $\mathrm{H}_{2} \mathrm{~S}$ (SIM) was not produced.

Fermentation products. Fermentation products (average milliequivalents per $100 \mathrm{ml}$ of culture) were as follows.

From PY-glucose: Formic (1.5 to 2.0), butyric (0.9), lactic (0.7), and acetic (0.5) acids, sometimes with ethanol and trace amounts of pyruvic and succinic acids. Abundant hydrogen was produced.

From PY-pyruvate: Formate (1.3) and acetate $(0.8)$, sometimes with trace amounts of lactate, butyrate, and succinate.

From PY: Occasionally trace amounts of acetic, succinic, or butyric acids.

Threonine was not converted to propionate. Lactate and gluconate were not used.

G+C content of the DNA: $41 \mathrm{~mol} \%$ by $T_{m}$ for the type strain.

TABLE 1. Characteristics of genera of Peptococcaceae Rogosa ${ }^{a}$

\begin{tabular}{|c|c|c|c|c|c|c|}
\hline Genus & $\begin{array}{c}\text { Cell } \\
\text { arrangement }\end{array}$ & $\begin{array}{l}\text { Peptone, a } \\
\text { major energy } \\
\text { source }\end{array}$ & $\begin{array}{l}\text { Carbohydrate } \\
\text { fermented }\end{array}$ & $\begin{array}{l}\text { Lactic, the } \\
\text { sole major } \\
\text { acid product }\end{array}$ & $\begin{array}{l}\text { Butyric or other } \\
3+\text { carbon vola- } \\
\text { tile acids produced }\end{array}$ & $\begin{array}{c}\mathrm{Mol} \% \\
\mathrm{G}+\mathrm{C} \\
\left(T_{m}\right)\end{array}$ \\
\hline Peptococcus & $\begin{array}{l}\text { Diplococci, } \\
\text { short chains }\end{array}$ & + & -+ & - & $v$ & $36-37^{b}$ \\
\hline $\begin{array}{l}\text { Peptostrep- } \\
\text { toccus }\end{array}$ & Chains & + & +- & - & $\mathrm{v}$ & $33-35$ \\
\hline Coprococcus & $\begin{array}{l}\text { Diplococci, } \\
\text { chains }\end{array}$ & - & $\mathrm{sr}$ & - & + & $39-42$ \\
\hline Ruminococcus & $\begin{array}{l}\text { Diplococci, } \\
\text { chains }\end{array}$ & - & $r$ & - & - & $40-45$ \\
\hline Sarcina & Packets & - & r & - & $\mathrm{v}$ & $29-31$ \\
\hline
\end{tabular}

${ }^{a}$ In part from Rogosa (14). Symbols: - , Negative reaction; + , positive reaction; r, required; sr, stimulatory or required; v, variable. Where two reactions are given (e.g., "+-"), the first is the more usual and the second is observed less frequently.

b As reported by Rogosa (14). 
INT. J. SYST. BACTERIOL.

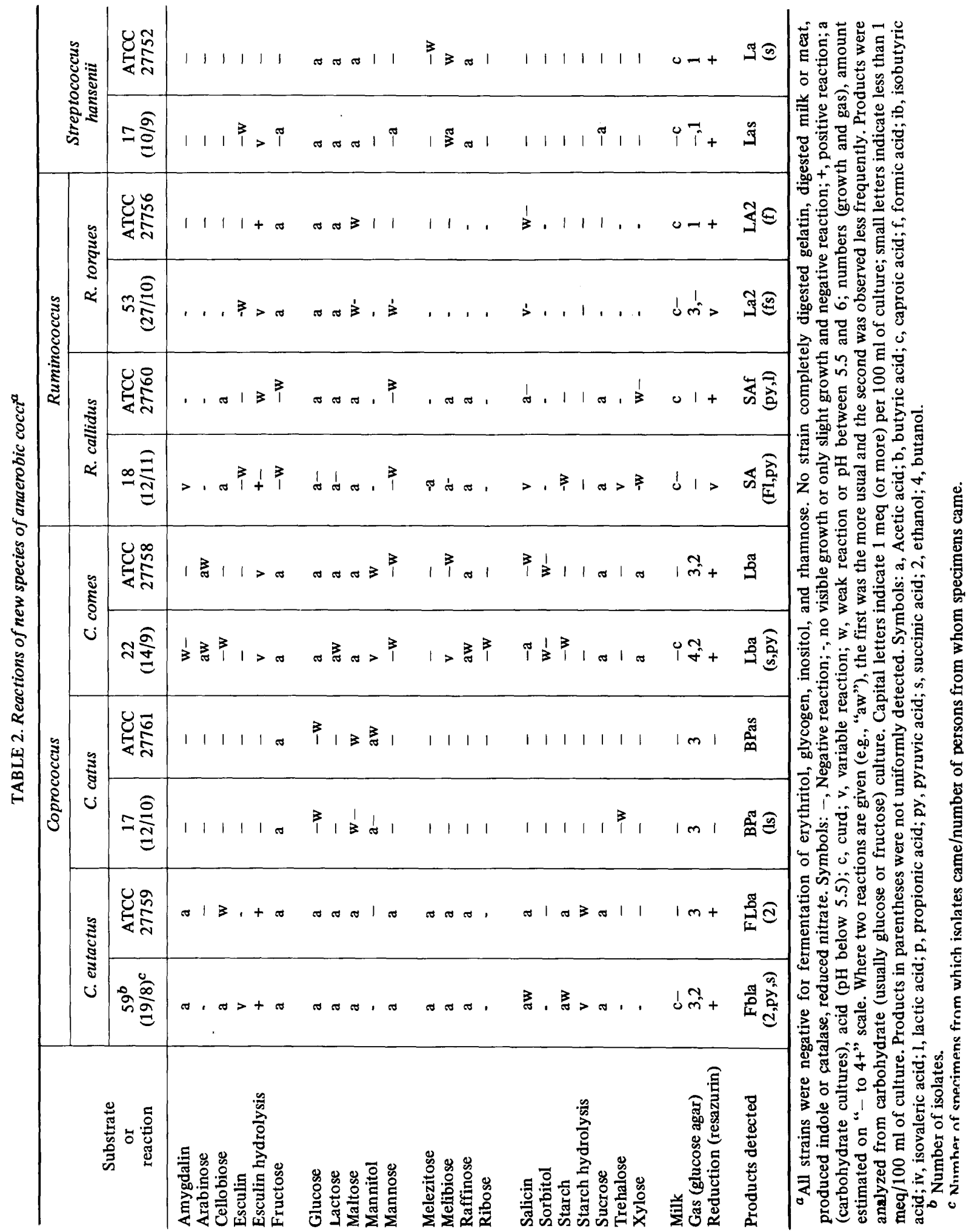


Type strain: American Type Culture Collection (ATCC) 27759 (= Virginia Polytechnic Institute [VPI] C33-22); isolated from human feces.

This species is easily recognized by its production of formic, lactic, and butyric acids from glucose, by its poor growth in the absence of fermentable carbohydrates, and by its rather uniform fermentation of the substrates indicated above.

(ii) Coprococcus catus sp. nov. (L. adj. ca'tus clever [referring to the unusual property of producing large quantities of both propionic and butyric acids].) Obligately anaerobic, nonmotile, gram-positive, slightly elongate cocci which usually occur in pairs that form long chains (Fig. 2). Cells of unequal size could occur in the pairs. The average cell size in PY-glucose cultures was 1.1 by $1.7 \mu \mathrm{m}$; the range of cell size was 0.8 to 1.4 by 1.6 to 1.9 $\mu \mathrm{m}$.

Colonies. After incubation for 5 days in RGCA roll tubes, colonies were 0.5 to $1 \mathrm{~mm}$ in diameter, lenticular (occasionally trifoleate), and white to $\tan$.

On anaerobic BAP incubated for 2 days, surface colonies of the type strain were 0.5 to 1 $\mathrm{mm}$ in diameter, circular, erose, umbonate, opaque, smooth, shiny, and white, and produced slight alpha-hemolysis. There was no growth on BAP incubated in a candle jar or in an aerobic atmosphere.

Cultural characteristics. Slight to moderate growth occurred in PY broth. PY-fructose cultures had abundant growth with some turbidity and a smooth, crumb-like, or slightly ropy sediment; after incubation for 5 days, the $\mathrm{pH}$ was 4.8 to 5.5 . Although the $\mathrm{pH}$ in glucose broth did not go below 6.0 , growth usually was stimulated by glucose, and propionate and butyrate production exceeded that of PY cultures.

There was little growth in PY-6.5\% NaClglucose broth. Growth in PY-glucose was not affected by $20 \%$ bile, $0.1 \%$ Tween 80 , or $10 \%$ rumen fluid.

There was usually no growth at $30 \mathrm{C}$; good

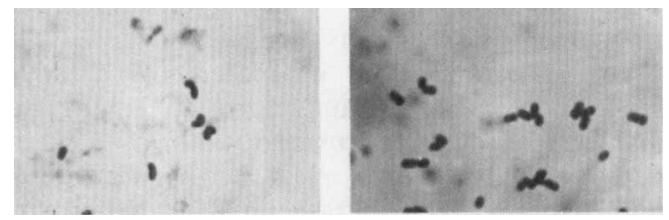

FIG. 1. Coprococcus eutactus. Left, cells from $P Y$ broth culture. Right, cells from PY-glucose broth culture. See Fig. 16 for scale.

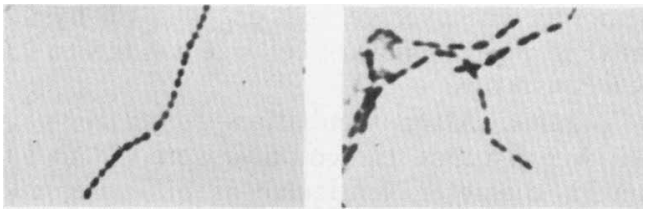

FIG. 2. Coprococcus catus. Left, cells from $P Y$ fructose broth culture. Right, cells from PY-glucose broth culture. See Fig. 16 for scale.

growth occurred at 37 and $45 \mathrm{C}$.

Biochemical reactions. The characteristics of 17 isolates of this species are given in Table 2. In addition, the type strain and four other strains tested did not ferment adonitol, dextrin, dulcitol, glycerol, inulin, or sorbose; did not produce $\mathrm{H}_{2} \mathrm{~S}$ (SIM), lecithinase, lipase (EYA), $\mathrm{AMC}$, or urease; and did not hydrolyze hippurate. Neutral red was reduced. Galactose was very weakly fermented by two strains but not by the type strain and two other strains tested. Ammonia was not produced from cultures in chopped meat, PY, or arginine medium, but small amounts were sometimes detected in PY-glucose and PY-gluconate cultures.

Fermentation products. Fermentation products (average milliequivalents per $100 \mathrm{ml}$ of culture) were as follows.

From PY-fructose: Butyric (5 to 7) and propionic ( 1 to 2 ) acids with trace amounts of acetic acid and sometimes lactic and succinic acids. Abundant hydrogen was produced.

From PY-lactate: Propionate (greater than 3.5 ), acetate (2), and butyrate (1.5), sometimes with very slight amounts of succinate, pyruvate, isobutyrate, or isovalerate.

From PY-pyruvate: Acetate (3.5), butyrate (2), and propionate (1), sometimes with trace amounts of lactate, succinate, isobutyrate, or valerate.

From PY: Butyrate (0.3), with trace amounts of propionate, succinate, and acetate.

Threonine was not converted to propionate; gluconate was not used.

G+C content of the DNA: $41 \mathrm{~mol} \%$ by $T_{m}$ for the type strain and $39 \mathrm{~mol} \%$ for VPI C1-32.

Type strain: ATCC 27761 (= VPI C6-61); isolated from human feces.

This species is easily recognized by its production of large amounts of butyric and propionic acids from fructose.

(iii) Coprococcus comes sp. nov. (L. no. co'mes companion, fellow traveler [referring to the presence of this species in human feces].) Obligately anaerobic, nonmotile, gram-positive, elongate cocci with tapered ends. Cells occurred singly and in pairs and chains of 4 to 20 
elements. The average cell size was 1.6 by 2.3 $\mu \mathrm{m}$ (Fig. 3); the range of cell size was 0.8 to 2.0 by 0.8 to $5 \mu \mathrm{m}$.

Colonies. After incubation for 5 days in RGCA roll tubes, the colonies were 0.5 to 1.0 $\mathrm{mm}$ in diameter, lenticular or bifoleate, and translucent.

On anaerobic BAP incubated for 2 to 3 days, surface colonies of the type strain were 0.5 to $1.0 \mathrm{~mm}$ in diameter, circular, entire, convex, opaque, smooth, shiny, and white with slight alpha-hemolysis. Other strains of the species were nonhemolytic on sheep blood agar. There was no growth on BAP incubated in a candle jar or in an aerobic atmosphere.

Cultural characteristics. There was only moderate growth in PY broth without fermentable carbohydrate. PY-glucose cultures had a smooth (sometimes stringy) sediment with no or only moderate turbidity; after incubation for 1 day, the $\mathrm{pH}$ was 4.8 to 5.2 .

No growth occurred in PY-6.5\% NaCl-glucose broth. Growth was usually slightly inhibited by $20 \%$ bile. Growth in PY-glucose was unaffected by $0.1 \%$ Tween 80 or $10 \%$ rumen fluid.

The temperature for optimal growth was 37 $\mathrm{C}$; most strains grew well at 45 but not $30 \mathrm{C}$.

Biochemical reactions. The characteristics of 22 isolates of this species are given in Table 2. In addition, the type strain and six other strains tested did not ferment adonitol, dextrin, glycerol, or sorbose and did not hydrolyze hippurate or produce AMC. Neutral red was reduced. Small to moderate amounts of ammonia were produced in chopped meat and PY cultures; no ammonia was detected from arginine or PY-glucose cultures. The type strain and five of six other strains tested fermented galactose. $\mathrm{H}_{2} \mathrm{~S}$ (SIM) was not produced by the type strain or by four of six other strains tested. The fermentation of inulin was variable. Growth on EYA was variable; no lecithinase or lipase was produced by strains that grew on this medium.

Fermentation products. Fermentation products (average milliequivalents per $100 \mathrm{ml}$ of culture) were as follows.

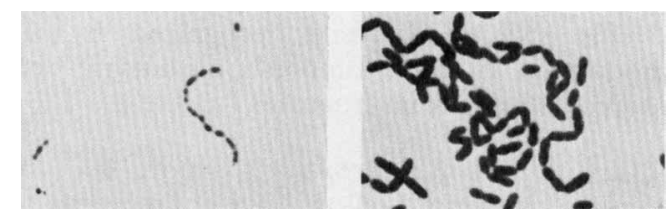

FIG. 3. Coprococcus comes. Left, cells from PY broth culture. Right, cells from PY-glucose broth culture. See Fig. 16 for scale.
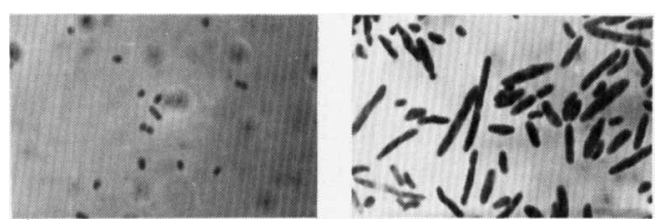

FIG. 4. Ruminococcus callidus. Left, cells from $P Y$ broth culture. Right, cells from PY-glucose broth, culture. See Fig. 16 for scale.

From PY-glucose: D(-) lactic (3.0), butyric $(0.7)$, and acetic $(0.5)$ acids, sometimes with small amounts of succinic and pyruvic acids. No hydrogen was detected.

From PY-pyruvate: Acetate (5) and butyrate (1 to 2), sometimes with formate.

From PY: Acetic (1.5) and butyric (0.2) acids, sometimes with trace amounts of pyruvic, lactic, and succinic acids.

Threonine was not converted to propionate. Lactate and gluconate were not utilized.

G + C content of the DNA: $40 \mathrm{~mol} \%$ by $T_{m}$ for the type strain; $42 \mathrm{~mol} \%$ for VPI B2-51.

Type strain: ATCC 27758 (= VPI C1-38); isolated from human feces.

This species is easily recognized by its production of lactic and butyric acids from glucose. Its fermentation of arabinose and xylose help differentiate it from the other two species in the genus.

\section{New species of the genus Ruminococcus}

Descriptions of new species of Ruminococcus are given in Table 2 and in the following discussion.

(i) Ruminococcus callidus sp. nov. (G. Adj. cal'li.dus clever, expert [referring to the proclivity of this species to attack di- and trisaccharides].) Obligately anaerobic, nonmotile, grampositive cocci, 1.0 to 1.6 by 1.8 to $2.0 \mu \mathrm{m}$, usually occurring in pairs (sometimes short chains) with the adjacent ends of the pair rounded and the other ends slightly tapered (Fig. 4).

Colonies. After incubation for 5 days in RGCA roll tubes, colonies were 0.2 to $1.0 \mathrm{~mm}$ in diameter, white to tan, translucent to transparent, and lenticular. Surface colonies were 2 to $3 \mathrm{~mm}$ in diameter, flat, and translucent with scalloped edges.

On anaerobic BAP incubated for 5 days, surface colonies are punctiform to $1.5 \mathrm{~mm}$ in diameter, circular to irregular, umbonate, white with yellowish center, clear, with an entire or undulate edge, and beta-hemolytic. No growth occurred on BAP incubated in a candle jar or in an aerobic atmosphere. 
Cultural characteristics. There was no or poor growth in PY broth without fermentable carbohydrate. PY-maltose cultures had a smooth to grainy sediment with little or no turbidity; after incubation for 5 days, the $\mathrm{pH}$ was 4.8 to 5.5 .

Growth in PY-glucose was somewhat inhibited by $20 \%$ bile, but it was not affected by $0.1 \%$ Tween 80 or $10 \%$ rumen fluid.

The temperature for optimal growth was 37 $\mathrm{C}$; growth was irregular at 30 and $45 \mathrm{C}$.

Biochemical reactions. The characteristics of 18 isolates of this species are given in Table 2 . In addition, the type strain and five other strains tested did not produce ammonia in PY, PY-glucose, or arginine cultures, did not produce $\mathrm{H}_{2} \mathrm{~S}$ (SIM), did not hydrolyze hippurate, and did not produce lecithinase or lipase (EYA). The type and one of five other strains tested did not produce AMC, but four strains did. The type and five of five other strains tested did not produce acid from adonitol, dulcitol, galactose, or sorbitol. Two strains weakly fermented dextrin. Of six strains tested, the type and one other strain fermented inulin.

Fermentation products. Fermentation products (average milliequivalents per $100 \mathrm{ml}$ of culture) were as follows.

From PY-fermentable carbohydrate (maltose, glucose, fructose, or cellobiose): Succinic (3.0) and acetic (1.4) acids, usually with formic (0.6 to 1.7) and trace to moderate amounts of lactic and pyruvic acids. Abundant hydrogen was produced from maltose.

Essentially no products were detected from PY cultures (poor growth). Lactate, pyruvate, and gluconate were not used.

G+C content of the DNA: $43 \mathrm{~mol} \%$ by $T_{m}$ for the type strain.

Type strain: ATCC 27760 (= VPI S7-31); isolated from feces.

Because this species requires a fermentable carbohydrate for good growth or continued subculture and produces succinic and acetic acids, it is placed in the genus Ruminococcus. It differs from other described species in the genus by fermenting raffinose and from $R$. flavefaciens, which it most closely resembles, by fermenting maltose.

(ii) Ruminococcus torques sp. nov. (L. n. tor'ques twisted necklace [referring to appearance of the chains from broth cultures].) Obligately anaerobic, nonmotile, gram-positive, spherical to oval cells occurring in pairs and short chains. Cells of the type strain were 0.3 to $0.6 \mu \mathrm{m}$ in diameter. Cell size ranged from 0.3 to $0.9 \mu \mathrm{m}$ (Fig. 5).
Colonies. After incubation for 5 days in RGCA roll tubes, colonies were 0.5 to $1.0 \mathrm{~mm}$ in diameter, white to tan, translucent (sometimes transparent) and lenticular to multifoleate.

On anaerobic BAP incubated for 2 days, surface colonies of the type strain were punctiform to $1.5 \mathrm{~mm}$ in diameter, circular, entire, low-convex, white, translucent, shiny, smooth, and nonhemolytic. There was no growth on BAP incubated in a candle jar or in an aerobic atmosphere.

Cultural characteristics. Slight to moderate growth occurred in PY broth. PY-glucose cultures had a smooth or ropy sediment and often there was no turbidity; after incubation for 1 to 3 days, the $\mathrm{pH}$ was 4.6 to 5.0 .

Growth in PY-glucose usually was unaffected by addition of rumen fluid, $20 \%$ bile, or $0.1 \%$ Tween 80 . However, the $\mathrm{pH}$ was slightly lower in the presence of Tween 80 .

The temperature for optimal growth was 37 $\mathrm{C}$; strains usually grew well at $45 \mathrm{C}$, but growth was variable at $30 \mathrm{C}$.

Biochemical reactions. The characteristics of 53 isolates of this species are given in Table 2. In addition, the type strain and three other strains tested fermented galactose and reduced neutral red. They did not ferment adonitol, dextrin, dulcitol, glycerol, inulin, or sorbose and did not produce AMC, lecithinase or lipase (EYA), hydrolyze hippurate, or grow in PY$6.5 \% \mathrm{NaCl}$-glucose broth. The type strain and one of three other strains tested produced a small amount of ammonia from chopped meat.

Fermentation products. Fermentation products (average milliequivalents per $100 \mathrm{ml}$ of culture) were as follows.

From PY-glucose: DL-Lactic (2.4) and acetic (0.7) acids and ethanol, usually with formic (0.7) and sometimes with trace amounts of succinic acids. Abundant hydrogen was produced.

From PY-pyruvate: Acetate (2.7) and formate (1.7), sometimes with lactate (0.9).

From PY: Little or no acetic, lactic, and/or succinic acids.

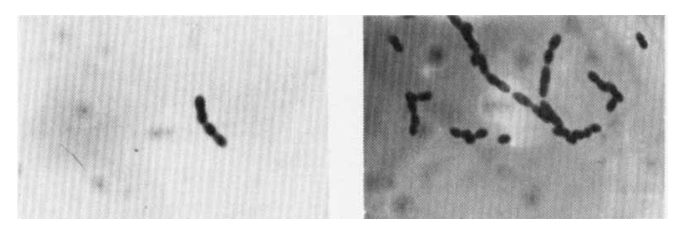

FIG. 5. Ruminococcus torques. Left, cells from $P Y$ broth culture. Right, cells from PY-glucose broth culture. See Fig. 16 for scale. 
Lactate and gluconate were not utilized. No propionate was produced from threonine.

G $+C$ content of the DNA: $42 \mathrm{~mol} \%$ by $T_{m}$ for the type strain; $40 \mathrm{~mol} \%$ for VPI C14-52.

Type strain: ATCC 27756 (= VPI B2-51); isolated from human feces.

The production of abundant hydrogen and often relatively large amounts of acetic acid exclude this organism from the genus Streptococcus.

New species, new combinations, and emended descriptions of anaerobic members of the genus Streptococcus

Although the species of the genus Streptococcus as listed in the 7th edition of Bergey's Manual of Determinative Bacteriology are all facultatively anaerobic, we concur with the recommendation of Rogosa (14) that obligately anaerobic species of cocci which occur in chains and that are fermentative and produce lactic acid as the major product (with or without small amounts of acetic or formic acids, ethanol, $\mathrm{CO}_{2}$ ) should properly be included in the genus Streptococcus. Following this recommendation, the species presently known as Peptostreptococcus intermedius is returned to the genus Streptococcus, where it was originally placed by Prevot (10). The species Peptostreptococcus morbillorum (16), placed in Diplococcus (11) and Peptococcus (4), and the species Peptococcus constellatus (1), originally placed in Diplococcus (9), also produce lactic acid as the sole major fermentation product and therefore are placed in the genus Streptococcus, along with Streptococcus hansenii sp. nov., a species isolated from the intestinal tract.

A description of Streptococcus hansenii sp. nov. is given in Table 2 and in the following discussion. Emended descriptions of Streptococcus constellatus (Prévot) comb. nov., Streptococcus intermedius Prévot, and Streptococcus morbillorum (Prévot) comb. nov. are given in Table 3 and in the following discussion.

(i) Streptococcus hansenii sp. nov. (M.L. gen. n. han.sen'i.i of Hansen (named for P. Arne Hansen, a Danish-American bacteriologist].) Obligately anaerobic, nonmotile, gram-positive cocci, with rounded or slightly tapered ends, which occurred in pairs or chains of pairs. Cells of the type strain in glucose broth cultures were 1.6 to $2,3 \mu \mathrm{m}$ in diameter (Fig. 6).

Colonies. After incubation for 5 days in RGCA roll tubes, colonies were 0.5 to $2 \mathrm{~mm}$ in diameter, lenticular, and translucent or white with translucent edges.

On anaerobic BAP incubated for 2 days, surface colonies of the type strain were $2 \mathrm{~mm}$ in diameter, circular, entire, convex, opaque, shiny, smooth, and nonhemolytic. There was no growth on BAP incubated in a candle jar or in an aerobic atmosphere.

Cultural characteristics. PY-glucose broth cultures were usually turbid with a smooth or stringy sediment; after incubation for 5 days, the $\mathrm{pH}$ was 4.9 to 5.2 .

Growth was moderate to poor in PY broth. Growth in PY-glucose is unaffected by $0.1 \%$ Tween $80,10 \%$ rumen fluid, or $20 \%$ bile.

There was good growth in PY-glucose at 37 and $45 \mathrm{C}$, poor to moderate growth at $30 \mathrm{C}$, and usually no growth at $25 \mathrm{C}$.

Biochemical reactions. The characteristics of 17 isolates of this species are given in Table 2 . In addition, the type strain and four other strains tested fermented galactose and inulin and reduced neutral red. They did not produce acid in adonitol, dextrin, dulcitol, glycerol, or sorbose and did not hydrolyze hippurate. They did not grow in $6.5 \% \mathrm{NaCl}$-glucose broth and did not produce lecithinase or lipase (EYA). No ammonia, or only a slight amount, was produced in chopped meat cultures. The type and one of four other strains tested produced $\mathrm{H}_{2} \mathrm{~S}$ (SIM). AMC was produced by one of four strains tested.

Fermentation products. Fermentation products (average milliequivalents per $100 \mathrm{ml}$ of culture) were as follows.

From PY-glucose: D(-)-Lactic (4.0), acetic $(0.5)$, and succinic $(0.2)$ acids. No hydrogen was detected.

From PY-pyruvate: Lactate (1.3) and acetate (1.8).

From PY: Acetic (0.3) acid, with trace amounts of succinic and lactic acids.

Lactate and gluconate were not utilized. No propionate was produced from threonine.

G+C content of the DNA: $38 \mathrm{~mol} \%$ by $T_{m}$ for the type strain and $37 \mathrm{~mol} \%$ for VPI C9-30.

Type strain: ATCC 27752 (= VPI C7-24); isolated from human feces.

This species ferments lactose, unlike $S$. constellatus and $S$. morbillorum, and does not ferment cellobiose, unlike S. intermedius.

(ii) Streptococcus constellatus (Prévot) comb. nov. [Syns.: Peptococcus constellatus (Prévot) Douglas 1957; Diplococcus constellatus Prévot 1924]. Anaerobic to aerotolerant, nonmotile, nonsporeforming, gram-positive cocci which are round to slightly oval and occur in pairs and short chains. Cells in the pairs could be of very unequal size; some appeared to be "budding." The average size of cells was 0.8 to $1.3 \mu \mathrm{m}$; the 
TABLE 3. Reactions of species of anaerobic-to-aerotolerant streptococci ${ }^{a}$

\begin{tabular}{|c|c|c|c|c|c|c|c|c|c|}
\hline \multirow[b]{2}{*}{$\begin{array}{l}\text { Substrate } \\
\text { or } \\
\text { reaction }\end{array}$} & \multicolumn{3}{|c|}{ S. constellatus } & \multicolumn{3}{|c|}{ S. intermedius } & \multicolumn{3}{|c|}{ S. morbillorum } \\
\hline & $\begin{array}{l}\text { Original } \\
\text { descrip- } \\
\text { tion }^{b}\end{array}$ & $\begin{array}{l}\text { Type } \\
\text { strain }\end{array}$ & $\begin{array}{c}7 \\
\text { strains }\end{array}$ & $\begin{array}{c}\text { Original } \\
\text { descrip- } \\
\text { tion }\end{array}$ & $\begin{array}{l}\text { Type } \\
\text { strain }\end{array}$ & $\begin{array}{c}63 \\
\text { strains }\end{array}$ & $\begin{array}{l}\text { Original } \\
\text { descrip- } \\
\text { tion }\end{array}$ & $\begin{array}{l}\text { Type } \\
\text { strain }\end{array}$ & $\begin{array}{c}9 \\
\text { strains }\end{array}$ \\
\hline Amygdalin & & $\mathbf{a}$ & $-\mathrm{a}$ & & $\mathrm{v}$ & $-\mathbf{a}$ & & w & w- \\
\hline Arabinose & a & - & - & $-^{e}$ & - & - & & - & - \\
\hline Cellobiose & & $w-$ & aw & & $\mathrm{a}$ & aw & & - & $-w$ \\
\hline Dextrin & & $w-$ & $\mathrm{v}$ & & $w-$ & $\mathrm{v}$ & & - & $-w$ \\
\hline Esculin & & - & $-\mathbf{a}$ & & $\mathrm{v}$ & $-\mathbf{a}$ & & - & - \\
\hline Esculin hydrolysis & & + & + & & + & + & & - & - \\
\hline Fructose & a & $\mathrm{a}$ & a & a & $\mathrm{a}$ & a & $\mathrm{v}_{f}^{f}$ & - & $\mathbf{v}$ \\
\hline Galactose & a & a & a & a & $\mathrm{a}$ & $a$ & $v^{f}$ & - & $\mathrm{v}$ \\
\hline Glucose & $\mathrm{a}$ & $\mathrm{a}$ & $\mathrm{a}$ & a & a & a & a & $\mathbf{w}$ & aw \\
\hline Glycerol & $\mathrm{w}$ & - & - & & w- & $-w$ & $\mathrm{v}^{f}$ & - & - \\
\hline Glycogen & & - & - & & - & - & & - & $-w$ \\
\hline İnulin & - & - & - & & - & $-\mathbf{a}$ & & - & - \\
\hline Lactose & - & - & - & a & $\mathrm{a}$ & $a$ & & - & - \\
\hline Maltose & $\mathrm{a}$ & $\mathbf{a}$ & a & $\mathrm{a}$ & a & a & $\mathbf{a}$ & w & aw \\
\hline Mannitol & - & - & $-a$ & - & - & $-a$ & & - & - \\
\hline Mannose & & $\mathbf{a}$ & $\mathrm{a}$ & & $a$ & $a$ & & w & $\mathrm{v}$ \\
\hline Melezitose & & - & - & & $\mathbf{w}-$ & $-w$ & & - & $-w$ \\
\hline Melibiose & & - & - & & - & $\mathrm{v}$ & & - & - \\
\hline Raffinose & & - & - & & - & $\mathrm{v}$ & & - & $-w$ \\
\hline Ribose & & - & $-\mathbf{a}$ & & $-w$ & $-\mathbf{a}$ & & - & $\mathbf{v}$ \\
\hline Salicin & & $\mathrm{a}$ & aw & & $\mathrm{a}$ & $a-$ & & - & - \\
\hline Starch & & $\mathrm{a}$ & aw & - & $\mathrm{v}$ & $\mathrm{v}$ & $v^{f}$ & - & $w-$ \\
\hline Starch hydrolysis & & - & - & & - & $\mathrm{v}$ & & - & - \\
\hline Sucrose & a & $\mathbf{a}$ & a & $\mathbf{v}$ & $\mathrm{a}$ & $\mathrm{a}$ & $\mathbf{a}$ & 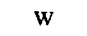 & aw \\
\hline Trehalose & & $\mathrm{a}$ & aw & & $\mathbf{a}$ & $a-$ & & - & - \\
\hline Xylose & & - & $-\mathrm{a}$ & & - & $-w$ & & - & $-w$ \\
\hline Gelatin digestion & - & - & - & - & $-w$ & $-\mathrm{w}$ & & - & $-w$ \\
\hline Milk & - & - & - & $\mathrm{c}$ & c & $\mathrm{c}$ & $-\mathrm{c}$ & - & - \\
\hline Gas & - &,- 1 &,- 2 & - & - & - & & - &,- 2 \\
\hline Acetylmethylcarbinol & $+f$ & - & - & & +- & -+ & & $\mathrm{v}$ & $-\mathbf{w}$ \\
\hline Neutral red reduction & - & - & - & + & - & $\mathrm{v}$ & & - & $\mathbf{v}$ \\
\hline
\end{tabular}

${ }^{a}$ None of these strains tested in our laboratory produced acid from adonitol, dulcitol, erythritol, inositol, rhamnose, sorbitol, or sorbose; none produced $\mathrm{H}_{2} \mathrm{~S}$, reduced nitrate, or digested meat. See Table 2 for symbols.

b Prévot (9).

${ }^{c}$ Prévot (10).

d Prévot (11).

e Prévot, 1933 (11); arabinose attacked by strains from appendicitis.

$f$ From Prévot et al. (13).

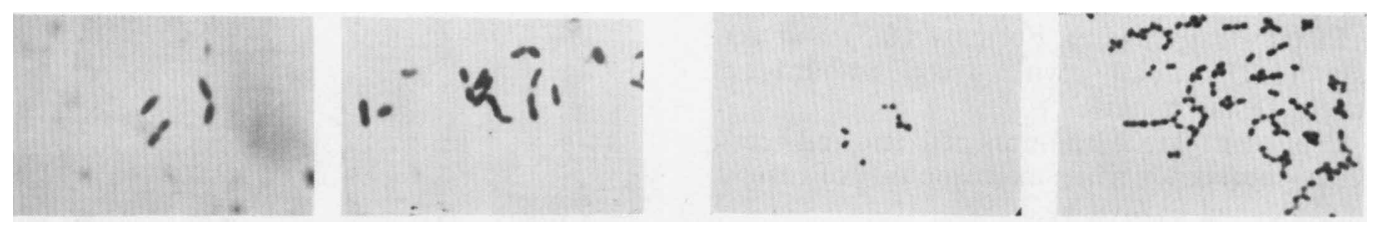

FIG. 6. Streptococcus hansenii. Left, cells from $P Y$ broth culture. Right, cells from PY-glucose broth culture. See Fig. 16 for scale.
FIG. 7. Streptococcus constellatus. Left, cells from $P Y$ broth culture. Right, cells from PY-glucose broth culture. See Fig. 16 for scale. 
range of cell size was 0.5 to 1.3 by 0.8 to 2.4 $\mu \mathrm{m}$ in PY-glucose broth cultures (Fig. 7).

Colonies. On anaerobic BAP incubated for 2 to 3 days, surface colonies of the type strain were 0.5 to $2 \mathrm{~mm}$ in diameter, circular, entire to slightly umbonate, convex, translucent, shiny, smooth, and nonhemolytic. Slight hemolysis was observed with other strains (some tested on horse blood agar).

Cultural characteristics. PY broth cultures had light to moderate turbidity. PY-glucose cultures had abundant growth with granular or smooth sediment; after incubation for 5 to 7 days, the $\mathrm{pH}$ was 4.4 to 5.0 . There was poor growth in $\mathrm{PY}-6.5 \% \mathrm{NaCl}$-glucose broth and PY-glucose-bile broth. Growth usually was not enhanced by Tween 80 .

After several laboratory transfers, three of seven strains tested grew on the surface of BAP incubated aerobically, and four of five strains tested grew on the surface of BAP incubated in a candle jar. The neotype strain did not grow on the aerobic plates but sometimes produced slight growth on the surface of plates incubated in the candle jar. The ability to grow in an aerobic atmosphere may vary with the age and amount of inoculum.

The temperature for optimal growth was 35 to $37 \mathrm{C}$; good growth occurred at $30 \mathrm{C}$, but only slight growth occurred at 25 and $45 \mathrm{C}$.

Biochemical reactions. In addition to the reactions listed in Table 3 , the neotype strain and six other strains of this species did not produce $\mathrm{H}_{2} \mathrm{~S}$, catalase, lecithinase or lipase (EYA), or hydrolyze hippurate. Ammonia was usually detected from cultures in chopped meat, arginine, and PY. The neotype strain did not produce urease. No diaminopimelic acid was detected in whole-cell hydrolysates of the neotype strain, indicating that none is present in the cell wall (C. S. Cummins, personal communication).

Fermentation products. Fermentation products (average milliequivalents per $100 \mathrm{ml}$ of culture) were as follows.

From PY-glucose: Lactic (5.5) and acetic (0.2) acids, sometimes with trace amounts of formic and succinic acids. A trace of hydrogen was produced.

From PY-pyruvate: Formate (6.5) and acetate (5.0), usually with trace amounts of succinate and lactate.

From PY: Trace amounts of lactic and acetic acids, sometimes with small amounts of formic, succinic, and pyruvic acids.

Lactate was not utilized. Threonine was not converted to propionate.

Neotype strain: ATCC 27823 (= VPI $3810=$ Prévot 4055); a Prévot strain probably isolated from a case of purulent pleurisy.
Isolated from clinical specimens and vaginal swabs.

This species is most easily recognized by its production of lactic acid as a major product, its fermentation of glucose, maltose, and sucrose without fermentation of lactose, and its hydrolysis of esculin. Salicin fermentation has also been uniform in the strains tested.

Prévot first recognized this species by its formation of satellite colonies around a large central colony in deep agar cultures. The satellite phenomenon has not been noted when these strains were grown as surface colonies nor with the neotype strain in agar deep cultures in BHIA supplemented with yeast extract, vitamin $\mathrm{K}$, and hemin. Hare (3) also noted no satellite colonies.

In other characteristics, the reactions of the neotype strain conform to those given by Prévot et al. (13) except that we did not detect fermentation of arabinose or production of AMC. We found no fermentation of either L-arabinose or D-arabinose. Rogosa (Bergey's Manual, 8th ed., in press) stated that "a positive arabinose and a negative trehalose fermentation [as originally reported (9)] are in error; modern techniques show arabinose is not fermented and trehalose is fermented."

(iii) Streptococcus intermedius Prévot 1925, emended description. [Syn.: Peptostreptococcus intermedius (Prévot) Smith 1957]. Anaerobic to aerotolerant, nonmotile, nonsporeforming, gram-positive cocci occurring in chains. Cells are often somewhat elongate; cells in pairs may be of unequal size. The average size is 0.5 by $0.9 \mu \mathrm{m}$; the range of cell size is 0.3 to 0.8 by 0.5 to $1.5 \mu \mathrm{m}$ (Fig. 8 ).

Colonies. On anaerobic BAP incubated for 2 days, surface colonies of the type strain are 0.5 $\mathrm{mm}$ in diameter, circular, entire, convex, opaque, white, shiny, smooth, and nonhemolytic.

Cultural characteristics. There was moderate growth in PY broth, sometimes with a sediment. PY-glucose cultures had abundant growth and usually were turbid and had a sediment (smooth, grainy, flocculent, or stringy). After incubation for 3 to 5 days, the $\mathrm{pH}$ was 4.5 to

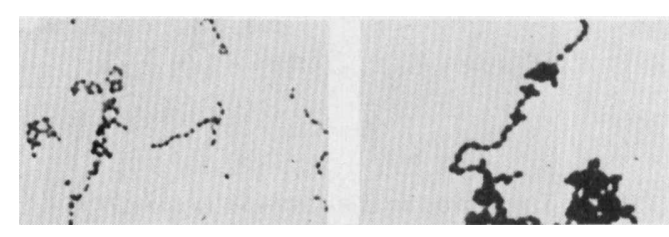

FIG. 8. Streptococcus intermedius. Left, cells from $P Y$ broth culture. Right, cells from PY-glucose broth culture. See Fig. 16 for scale. 
5.0 in PY-glucose cultures. Tween 80 enhanced growth of some strains, particularly fresh isolates. There was no or only slight growth in PY-6.5\% NaCl-glucose and PY-glucose-bile broths.

Of 50 strains of this species tested, four grew slightly on the surface of BAP incubated aerobically and two grew moderately well. Of 18 strains tested for surface growth on BAP incubated in a candle jar, one grew slightly, three grew moderately well, and one grew very well. The neotype strain produced moderate growth on BAP incubated in a candle jar, but there was no growth on BAP incubated in an aerobic atmosphere. The amount of growth in the candle jar varied with the age and amount of inoculum. Several strains were obligately anaerobic on initial isolation but grew rather well in the candle jar after several transfers.

The temperature for optimal growth was 35 to $37 \mathrm{C}$. Most strains grew well at 30 and $45 \mathrm{C}$. Only moderate or poor growth occurred at 25 C.

Biochemical reactions. In addition to the characteristics given for this species in Table 3, the neotype strain and 63 other strains tested did not produce $\mathrm{H}_{2} \mathrm{~S}$ (SIM). AMC production was variable by the neotype strain as well as by other strains. The neotype strain did not reduce neutral red; some of the other strains did. The neotype strain did not produce urease.

Fermentation products. Fermentation products (average milliequivalents per $100 \mathrm{ml}$ of culture) were as follows.

From PY-glucose: DL-Lactic acid [the amount of $\mathbf{L}(+)$-lactic exceeds the amount of D(-)-lactic acid] (6.0) often with acetic acid $(0.25)$ and sometimes with a small amount of succinic acid. No hydrogen was produced.

From PY-pyruvate: Formate (4.0) and acetate (3.5), sometimes with moderate amounts of lactate, and sometimes with small amounts of succinate.

From PY: Moderate amounts of lactic and acetic acids usually were produced, often with traces of succinic or formic acids.

G+C content of the DNA: $38.7 \mathrm{~mol} \%$ by chemical analysis (15) for the neotype strain.

Neotype strain: ATCC 27335 (= VPI 3372A

= Prévot 1877); the original source is unkown.

Isolated from numerous kinds of human clinical specimens and from feces.

The hydrolysis of esculin and the fermentation of cellobiose and lactose help differentiate $S$. intermedius from closely related species.

(iv) Streptococcus morbillorum (Prévot) comb. nov. [Syns.: Peptostreptococcus morbillorum (Prévot) Smith 1957; Diplococcus rubeolae Tunicliff 1933; Diplococcus morbillorum

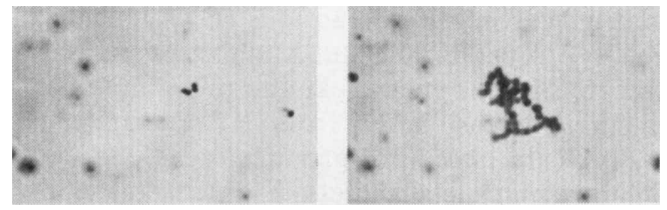

FIG. 9. Streptococcus morbillorum. Left, cells from PY broth culture. Right, cells from PY-glucose broth culture. See Fig. 16 for scale.

Prévot 1933]. Anaerobic to aerotolerant, nonmotile, nonsporeforming, gram-positive cocci which were often elongate and occurred in pairs and short chains. The cells in the pairs often were of unequal size. The average cell size in PY-glucose cultures was 0.5 by $1.2 \mu \mathrm{m}$; the range of cell size was 0.3 to 0.8 by 0.5 to 1.4 $\mu \mathrm{m}$ (Fig. 9).

Colonies. On anaerobic BAP incubated for 2 days, surface colonies of the neotype strain were pinpoint to $0.5 \mathrm{~mm}$ in diameter, circular, entire, convex, translucent, shiny, and smooth. The neotype strain was not hemolytic, but some of the other strains produced slight alpha-hemolysis.

Cultural characteristics. Only one of nine strains grew on the surface of BAP incubated aerobically or in a candle jar. The neotype and seven other strains tested did not grow on BAP incubated aerobically or in a candle jar. However, aerotolerant strains may occur more frequently than these results indicate because strains of facultative cocci usually are not referred to our laboratory for identification. Strains may be obligately anaerobic on first isolation. Not all strains, however, have become aerotolerant; the neotype strain still does not grow aerobically, even after numerous serial transfers in the laboratory and after freeze drying at least two times.

Fermentable carbohydrate and Tween 80 enhanced growth. There was only poor to moderate growth in PY-glucose cultures, but abundant growth with granular or smooth sediment was produced in PY-glucose-Tween 80 broth. Some strains had only sediment with no turbidity in PY-glucose-Tween 80 cultures. After incubation for 5 to 7 days, the $\mathrm{pH}$ was 4.8 to 5.4 in PY-glucose-Tween 80 cultures. Only moderate growth was produced in PY-Tween 80 broth medium. There was usually no growth in PY-6.5\% NaCl-glucose broth; many strains grew poorly in PY-glucose-bile broth.

The temperature for optimal growth was 35 to $37 \mathrm{C}$.

Biochemical reactions. In addition to the characteristics for this species given in Table 3, the neotype strain and eight other strains tested did not produce $\mathrm{H}_{2} \mathrm{~S}$ (SIM), AMC, catalase, or 
lecithinase or lipase reactions (EYA); they did not hydrolyze hippurate. Ammonia usually was detected in chopped meat and in arginine broth cultures, occasionally from PY cultures. The neotype strain did not produce urease.

Fermentation products. Fermentation products (average milliequivalents per $100 \mathrm{ml}$ of culture) were as follows.

From PY-glucose-Tween 80: Lactic (4.0) and acetic (0.6) acids, sometimes with formic and trace amounts of succinic and pyruvic acids, or ethanol. No hydrogen was produced.

From PY-pyruvate-Tween 80: Acetate (4.0), usually with formate (2.0), sometimes with lactate $(0.7)$ and trace amounts of succinate.

From PY-Tween 80: Small amounts of acetic acid, often with a trace of lactic acid, sometimes with a trace of formic, succinic, or pyruvic acids.

Lactate and gluconate were not utilized; threonine was not converted to propionate.

Neotype strain: ATCC 27824 (= VPI $5424=$ Prévot 2917B); a Prévot strain isolated from lung abscess.

Isolated from clinical specimens.

This species is most easily recognized by its production of lactic acid as a major product, and fermentation of glucose, maltose, and sucrose without fermentation of lactose or hydrolysis of esculin.

The characteristics of the neotype strain, which was isolated and identified by Prévot as $D$. morbillorum, conform to those given by Prévot et al. (13) except that we did not detect $\mathrm{H}_{2} \mathrm{~S}$ or propionate production. $\mathrm{H}_{2} \mathrm{~S}$ production varies considerably with different tests. We do not know which test was originally used. The gas chromatographic procedures currently used for analyses of fermentation acids give more precise identification of the compounds than did the earlier methods (presumably Duclaux distillation). From experience with other cultures, we know that identification by Duclaux analyses can be in error by one to two carbons. The propionate reported originally may have been formate. We therefore feel that the neotype strain here designated is representative of the species as originally described.

\section{* Anaerobic Rods}

A number of kinds of anaerobic rods that have not previously been describaed were encountered in the predominant flora. Among the gram-negative organisms, the presence of a fermentative Bacteroides species that failed to attack sucrose is an example. The application of DNA-DNA homology by competition experiments by Johnson ( 6 ; personal communication) to many strains of Bacteroides species has demonstrated that, at least among these organisms, different phenotypic patterns of carbohydrates fermented do indicate different genetic groups. This is fortunate, because much previous taxonomy has been based primarily upon carbohydrate utilization. We now have evidence and more confidence that such phenotypic observations do, in fact, correlate with genetically distinct kinds of bacteria. Unfortunately, within present phenotypic groups, there are sometimes more than one distinct genetic group. This indicates that there are even more distinctly different organisms than now can be differentiated phenotypically.

Among the gram-positive species, there are a number with strains that easily decolorize in older cultures and therefore may be among those that appear to be gram-negative in the original smears. Often there is considerable pleomorphism in cultures, but this varies with age of culture and from substrate to substrate and may, in part, reflect the higher oxidationreduction potential of the media as compared with that in the colon or rectum. The earlier descriptions by Eggerth (2) were exceedingly helpful and comprehensive enough to allow differentiation of morphologically similar yet physiologically distinct species described here.

\section{New species of Bacteroides}

Characteristics of Bacteroides eggerthii sp. nov. are given in Table 4 and in the following discussion.

(i) Bacteroides eggerthii sp. nov. (L. gen. $\mathrm{n}$. eg.gerth'i.i of Eggerth [named for Arnold $\mathbf{H}$. Eggerth, an American bacteriologist].) Obligately anaerobic, nonmotile, gram-negative, pleomorphic rods, ranging from coccoid to large rods with vacuoles or swellings, occurring singly or in pairs. Cells of the type strain were 1.1 to 1.6 by 1.6 to $9.4 \mu \mathrm{m}$; the sizes of six strains measured ranged from 0.4 to 1.1 by 0.8 to 14.0 $\mu \mathrm{m}$ in PY-glucose broth cultures (Fig. 10).

Colonies. After incubation for 5 days in RGCA roll tubes, colonies were 0.5 to $1.0 \mathrm{~mm}$ in diameter, white to tan, translucent, lenticular, occasionally multifoleate, and could have dark centers or spots.

On anaerobic BAP incubated for 2 days, surface colonies were punctiform, circular, entire, convex, translucent, grey-white, shiny, and smooth, and were nonhemolytic. No black pigment was observed on laked blood roll streaks after incubation for 8 days. No growth occurred on BAP incubated in a candle jar or in an aerobic atmosphere.

Cultural characteristics. Moderate to good growth occurred in PY-broth. PY-glucose broth 
VOL. 24, 1974

\begin{tabular}{|c|c|c|c|c|c|c|c|c|}
\hline \multirow{2}{*}{ 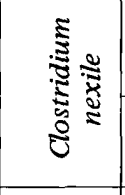 } & 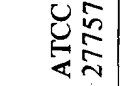 & $\geqslant 1 \mid B+$ & $3 \approx 1 \approx 1 \quad 1$ & & $1 \geqslant 1 \sigma 1 \sigma$ & 111 & $t+-N \mid \frac{\pi}{d}$ & \\
\hline & $=\frac{E}{S}$ & $3,13+$ & $\exists \sigma 1|c| 1$ & $1 \geqslant 101100$ & $13110 \%$ & $1 i 1$ & 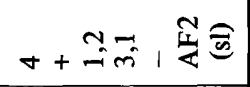 & \\
\hline \multirow{2}{*}{ 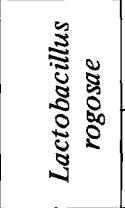 } & 蒽愛 & 111111 & $\begin{array}{llllll}0 & 1 & 1 & 1 & 1 & 1\end{array}$ & 111111111 & 11111111 & 111 & & \\
\hline & $a \frac{\hat{\infty}}{\infty}$ & $11 \pi, 1$ & $\vec{z} \mid 1>1$ & $1,11,1$ & 111,1 & 111 & $\begin{array}{c}1 \\
-i \\
-i\end{array}$ & \\
\hline \multirow{6}{*}{ 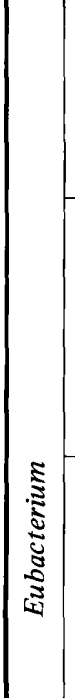 } & 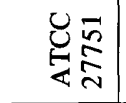 & $\begin{array}{llllll}1 & 1 & 1 & 1 & 1\end{array}$ & $\sigma \sigma \mid \sigma \geqslant \sigma$ & 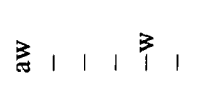 & $\begin{array}{llllll}\nexists & 1 & 1 & 1 & 1 & 1\end{array}$ & 111 & $++\stackrel{-}{*}+1$ 总总 & \\
\hline & $=\frac{6}{9}$ & 11111 & 寻灵，寻寻 & $3, \ldots, 1$. & 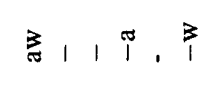 & $\begin{array}{lll}1 & 1 & 1\end{array}$ & $++-\stackrel{\text { m }}{*}$ । 总危 & \\
\hline & 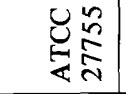 & $1 \approx 111$ & क ब 1 ब & $\begin{array}{llll}3 & 1 & 3 & 0 \\
\end{array}$ & 1111111 & $\begin{array}{lll}1 & \vdots & 1 \\
\end{array}$ & 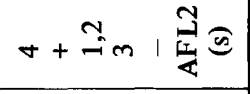 & \\
\hline & $\frac{0}{2}$ & $1>. .+$ & 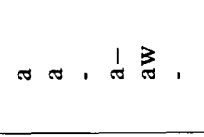 & $\geqslant, \pi \%$ &, $1 \%$ & $\begin{array}{lll}3 & 0 & 1\end{array}$ & F+c & \\
\hline & 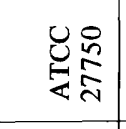 & $1, \infty 3+$ & $\pi, \mathbb{Z} \mid$ & $\$ \ldots$ & , ? . . & 101 & 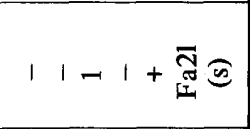 & \\
\hline & $8 \frac{\widehat{a}}{\grave{d}}$ & ，，寻主十 & 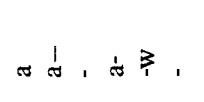 & $\%, 1, \%$ & , 蛋, , 平 & $\begin{array}{ll}1 & 1 \\
1 & 1\end{array}$ & 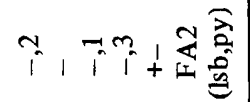 & \\
\hline \multirow{3}{*}{ 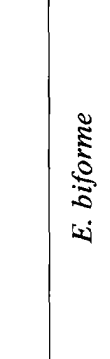 } & 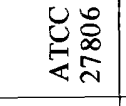 & $3,1,+$ & $\infty \pi, \infty 13$ & $\approx 1, \ldots$ & 1111,1 & $1 \quad 1 \quad 1$ & $N>\vec{r}_{m}^{+} 1=$ & \\
\hline & 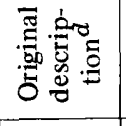 & $>1>>$ & $\approx \pi>>>\theta$ & $\sigma \quad 1>$ & $1>>\infty 1$ & 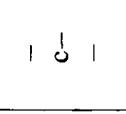 & & \\
\hline & 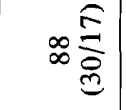 & $1111 \mid>$ & 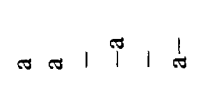 & $=1, \ldots$, & | | 1 i i | & $\begin{array}{ll}1 & 1\end{array}$ & 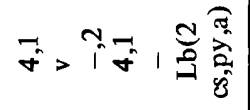 & \\
\hline \multirow{2}{*}{ 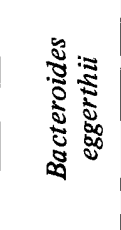 } & 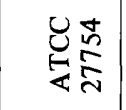 & 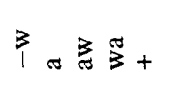 & $3 \pi \pi \approx \pi 1$ & $=11 ! 1$ & $10+110$ & $10+$ & 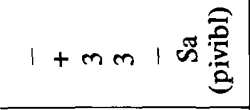 & \\
\hline & is & $\sum_{\infty}^{1} \Gamma_{1}^{\pi}>+$ & 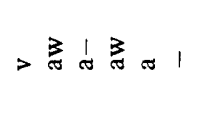 & $z_{1}^{3} 1>11$ & $1 a+112$ & $+0+$ & 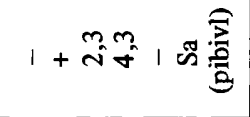 & \\
\hline & 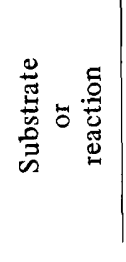 & 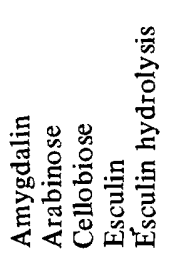 & 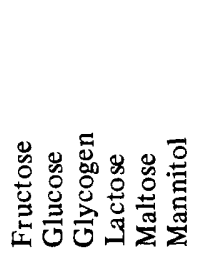 & 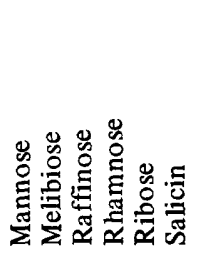 & 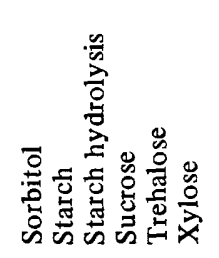 & 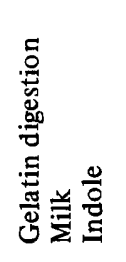 & 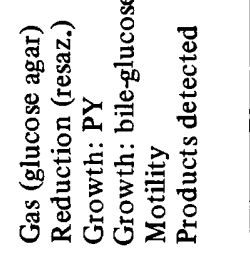 & \\
\hline
\end{tabular}



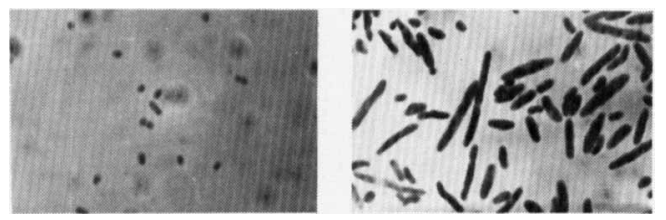

FIG. 10. Bacteroides eggerthii. Left, cells from $P Y$ broth culture. Right, cells from PY-glucose broth culture. See Fig. 16 for scale.

cultures were turbid with smooth (occasionally stringy) sediment, and the $\mathrm{pH}$ was 4.9 to 5.6 after incubation for 1 to 2 days. Growth in PY-glucose broth was generally unaffected by the addition of $10 \%$ rumen fluid or $0.1 \%$ Tween 80.

The temperature for optimal growth was 37 C. Good growth occurred at 30 and $45 \mathrm{C}$; moderate growth occurred at $25 \mathrm{C}$.

Biochemical reactions. The characteristics for 38 isolates of this species are given in Table 4. In addition, the type strain and seven other strains tested fermented dextrin and galactose and reduced neutral red. They did not ferment adonitol, dulcitol, glycerol, inulin, or sorbose. The eight strains tested did not produce AMC or urease, hydrolyze hippurate, grow in $6.5 \%$ $\mathrm{NaCl}$-glucose broth, or produce any reaction on EYA. Moderate ammonia was produced by the type strain and three of seven other strains tested. Moderate $\mathrm{H}_{2} \mathrm{~S}$ was detected in SIM medium with the type strain and four of seven other strains tested.

Fermentation products. Fermentation products (average milliequivalents per $100 \mathrm{ml}$ of culture) were as follows.

From PY-glucose: Succinic (3.8) and acetic (0.9) acids, often with a small amount of propionic and traces of lactic, isovaleric, and isobutyric acids. A trace amount of hydrogen was detected from eight of eight cultures tested.

From PY-pyruvate: Acetate (2.0) and succinate $(0.8)$ with trace to moderate amounts of propionate, isobutyrate, and isovalerate were usually produced.

From PY: Propionic (0.8), acetic (0.4), isovaleric $(0.3)$, succinic $(0.1)$, and isobutyric (0.1) acids.

Lactate and gluconate were not utilized. Small amounts of propionate were irregularly produced from threonine.

G+C content of the DNA: $46 \mathrm{~mol} \%$ by $T_{m}$ for the type strain and $44 \mathrm{~mol} \%$ for VPI B8-30.

Type strain: ATCC 27754 (= VPI T5-42B); isolated from human feces.

Although this organism morphologically resembles subspecies of Bacteroides fragilis, it is most easily recognized by its production of indole and by having a $\mathrm{pH}$ of 6.0 or above in sucrose and raffinose cultures.

Emended description and new species of Eubacterium

Characteristics of Eubacterium biforme and four new species of Eubacterium are given in Table 4 and in the following discussion.

(i) Eubacterium biforme (Eggerth) Prévot, 1938. Emended description. Obligately anaerobic, gram-positive, nonsporeforming, nonmotile coccobacilli occurring in pairs and chains. Cells of the type strain were 0.8 to 1.1 by 1.1 to $3.1 \mu \mathrm{m}$ in PY-glucose broth cultures (Fig. 11). Sizes of three other strains measured range from 0.6 to 2.7 by 1.6 to $15 \mu \mathrm{m}$. Rods and coccoid forms often occurred in the same chain. Central swellings ("pelton de jardinier") were seen in some cultures, particularly among cells from growth on solid media.

Colonies. After incubation for 5 days in RGCA roll tubes, colonies were 0.5 to $1.0 \mathrm{~mm}$ in diameter, white to tan, and usually lenticular and translucent, opaque, or translucent with opaque centers, sometimes with diffuse edges. Occasional colonies looked like white "woolly balls."

On anaerobic BAP after incubation for 2 days, surface colonies were 0.5 to $2.0 \mathrm{~mm}$ in diameter, circular, entire to slightly erose, flat to low convex, white, shiny, smooth, translucent with dense centers, and nonhemolytic. There was no growth on BAP incubated in a candle jar or in an aerobic atmosphere.

Cultural characteristics. No growth, or very poor growth, occurred in media without a fermentable carbohydrate. PY-glucose-Tween80 broth cultures had abundant growth with smooth sediment, usually without turbidity, and a $\mathrm{pH}$ of 4.5 to 5.0 in 1 to 2 days. Growth was enhanced by $0.1 \%$ Tween- 80 , but was not affected by addition of rumen fluid.

The temperature for optimal growth was 37 $\mathrm{C}$; some strains grew at $45 \mathrm{C}$, but most did not grow at $30 \mathrm{C}$.

Biochemical reactions. The characteristics for 88 isolates of this species are given in Table 4 . In addition, the type strain and eight of nine

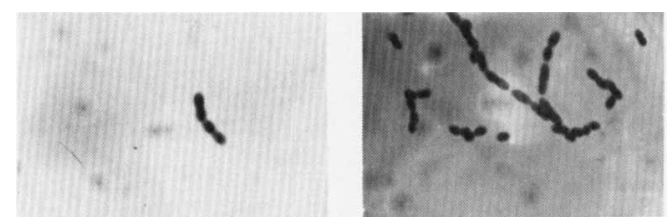

FIG. 11. Eubacterium biforme. Left, cells from $P Y$ broth culture. Right, cells from PY-glucose broth culture. See Fig. 16 for scale. 
other strains tested produced acid from galactose; all 10 reduced neutral red. The type and nine other strains tested did not ferment adonitol, dextrin, dulcitol, glycerol, inulin, or sorbose, and grew poorly in PY media to which these substrates had been added. The 10 strains tested did not produce AMC, hydrolyze hippurate, or produce $\mathrm{H}_{2} \mathrm{~S}$ in SIM medium. The type strain and four of nine other strains tested produced a small amount of ammonia in chopped meat cultures; none produced ammonia in PY-glucose cultures. Only 8 of 10 strains tested grew on EYA; they gave no reaction.

Fermentation products. Fermentation products (average milliequivalents per $100 \mathrm{ml}$ of culture) were as follows.

From PY-glucose-Tween 80: DL-Lactic (4.4) and butyric (0.7) acids, moderate ethanol, usually with caproic acid (0.1), occasionally with trace amounts of succinic, pyruvic, and acetic acids. Abundant hydrogen was produced. (Caproic acid was produced irregularly; production probably was dependent on the amount of growth and culture age. Most chromatographic analyses were made on 5-day-old cultures.)

From PY-pyruvate-Tween 80: Butyrate (1.5), often with lactate (0.14), and acetate (0.7), sometimes with formate and a small amount of caproate.

Lactate and gluconate were not utilized; threonine was not converted to propionate.

G+C content of the DNA: $32 \mathrm{~mol} \%$ by $T_{m}$ for the neotype strain.

Neotype strain: ATCC 27806 (= VPI C17-5); isolated from human feces.

This species is most easily recognized by its production of butyric and caproic (when detected) acids, along with a major amount of lactic acid. Lack of fermentation of arabinose and maltose help differentiate it from species which it most closely resembles.

(ii) Eubacterium eligens sp. nov. (L. adj. el'i.gens choosy [referring to its generally poor growth without fermentable carbohydrate].) Obligately anaerobic, gram-positive, nonsporeforming, straight to slightly curved rods, occurring singly or in pairs, occasionally in short chains of three to six cells. Central or eccentric swellings predominated in some strains. Twenty-four of 33 strains tested were motile and peritrichous. Cells decolorized easily in older cultures, but some gram-positive cells were usually seen. Cells of the type strain were 0.3 to 0.8 by 1.9 to $4.9 \mu \mathrm{m}$ in PY-glucose cultures (Fig. 12).

Colonies. After incubation for 5 days in RGCA, colonies were 0.5 to $1.0 \mathrm{~mm}$ in
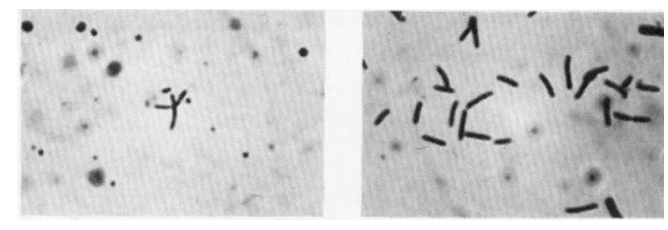

FIG. 12. Eubacterium eligens. Left, cells from $P Y$ broth culture. Right, cells from PY-glucose broth culture. See Fig. 16 for scale.

diameter, white to tan, and lenticular. Surface colonies on BHIA streak tubes were punctiform, circular, entire, transparent to translucent, white to tan, and smooth. Surface colonies on 2-day-old anaerobic BAP were 0.5 to $1.0 \mathrm{~mm}$ in diameter, circular, entire, convex, smooth, translucent to semi-opaque, shiny, white, and nonhemolytic. No growth occurred on inoculated BAP incubated in a candle jar or in an aerobic atmosphere.

Cultural characteristics. No growth, or only slight growth, was produced in PY broth without fermentable carbohydrate. PY-fructose broth cultures were turbid with smooth sediment and a pH of 4.6 to 5.8 in 5 days. Tween $80(0.1 \%)$ sometimes enhanced growth. Growth was not usually affected by addition of 10 to $30 \%$ rumen fluid.

The temperature for optimal growth was 37 C. Most strains grew well at $45 \mathrm{C}$; little or no growth was produced at $30 \mathrm{C}$.

Biochemical reactions. The characteristics for 69 isolates of this species are given in Table 4. In addition, the type strain and five other strains tested reduced neutral red. One produced weak acid from dextrin. They did not ferment adonitol, dulcitol, galactose, glycerol, inulin, or sorbose, and did not grow well in PY media to which these substrates had been added. The six strains tested did not produce $\mathrm{H}_{2} \mathrm{~S}$ (SIM) or ammonia. The type and three other strains tested did not produce AMC or hydrolyze hippurate. Only three of six strains tested grew on EYA; they gave no reaction.

Fermentation products. Fermentation products (average milliequivalents per $100 \mathrm{ml}$ of culture) were as follows.

From PY-glucose: Formic (1.8) and acetic (1.0) acids, and ethanol, often with lactic acid (0.35) and a trace amount of succinic acid, sometimes with traces of butyric or pyruvic acids. No hydrogen was detected.

From PY-pyruvate: Acetate (greater than 5.0 ), formate (greater than 3.0), lactate (1.2), and a moderate amount of ethanol.

From PY-gluconate: Formate (4.8), acetate (3.5), and ethanol, often with lactate (0.3) and a trace of succinate, sometimes with traces of pyruvate or butyrate. 
Usually no growth was produced in PY-lactate or in PY-threonine.

G + C content of the DNA: $36 \mathrm{~mol} \%$ by $T_{m}$ for the type strain (motile) and for VPI T1-52 (nonmotile).

Type strain: ATCC 27750 (= VPI C15-48); isolated from human feces.

$E$. eligens differs from $E$. aerofaciens by (i) the relatively small amount of lactate produced, (ii) extremely poor growth without fermentable carbohydrate, (iii) cellular morphology, (iv) motility (of some strains), and (v) lack of hydrogen production.

(iii) Eubacterium formicigenerans sp. nov. (N. L. adj. for.mi.ci.gen'er.ans formic-acidproducing [referring to its production of large amounts of formic acid from fermentation of carbohydrates].) Obligately anaerobic, grampositive, nonsporeforming, nonmotile rods occurring in chains or pairs. Cells of the type strain were 1.1 to 1.4 by 1.6 to $3.5 \mu \mathrm{m}$ in PY-glucose cultures (Fig. 13). The sizes of the five other strains measured ranged from 0.6 to 1.4 by 0.8 to $4.7 \mu \mathrm{m}$.

Colonies. After incubation for 5 days in RGCA, colonies were 0.5 to $1.0 \mathrm{~mm}$ in diameter, white to tan, circular to lenticular, and often had fuzzy edges or a "woolly ball" appearance. Surface colonies on BHIA streak tubes or anaerobic BAP were 0.5 to $3.0 \mathrm{~mm}$ in diameter, circular to slightly irregular, entire to slightly erose, convex to umbonate, opaque, white to tan, shiny, and smooth. Slight greening was produced on sheep BAP by the type strain, but the other six strains tested were nonhemolytic. No growth occurred on BAP incubated in a candle jar or in an aerobic atmosphere.

Cultural characteristics. Poor to moderate growth was produced in PY broth. PY-glucose broth cultures had stringy or flocculent (occasionally smooth) sediment with little or no turbidity and a $\mathrm{pH}$ of 4.7 to 5.0 in 5 days. Growth in PY-glucose was generally not affected by $0.1 \%$ Tween 80 or $10 \%$ rumen fluid.

The temperature for optimal growth was 37 C. Most strains grew moderately well at $30 \mathrm{C}$ and $45 \mathrm{C}$, but usually not at $25 \mathrm{C}$.

Biochemical reactions. In addition to the characteristics given for 22 isolates of this species in Table 4 , the type strain and six other strains tested reduced neutral red and produced acid from galactose. The type strain and two of six other strains tested hydrolyzed hippurate. The type strain and five of six others strains tested did not ferment dulcitol; one strain fermented dulcitol slightly. The type and six other strains tested did not ferment adonitol,

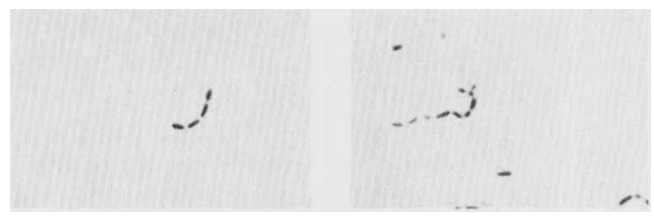

FIG. 13. Eubacterium formicigenerans. Left, cells from $P Y$ broth culture. Right, cells from PY-glucose broth culture. See Fig. 16 for scale.

dextrin, glycerol, inulin, or sorbose. They did not produce $\mathrm{H}_{2} \mathrm{~S}$ (SIM), AMC, ammonia, or urease. They did not grow in PY-6.5\% NaClglucose broth. The type strain and five of six other strains tested grew on EYA; they gave no reaction.

Fermentation products. Fermentation products (average milliequivalents per $100 \mathrm{ml}$ of culture) were as follows.

From PY-glucose: Acetic (1.9), formic (1.6), and lactic (0.9) acids and ethanol, sometimes with small amounts of succinic and pyruvic acids. Moderate to abundant hydrogen was produced.

From PY-pyruvate: Acetate (4.7), formate (1.7), and ethanol, usually with lactate $(0.3)$ and sometimes with a trace of succinate.

From PY: Acetic acid (0.5), sometimes with small amounts of lactic, succinic, or pyruvic acids.

Lactate and gluconate were not utilized; threonine was not converted to propionate.

G+C content of the DNA: $40 \mathrm{~mol} \%$ by $T_{m}$ for the type strain and $44 \mathrm{~mol} \%$ for VPI C34-11.

Type strain: ATCC 27755 (= VPI C8-13); isolated from human feces.

The fermentation acids and ethanol produced and lack of fermentation of cellobiose help differentiate $E$. formicigenerans from other species with which it might be confused.

(iv) Eubacterium hallii sp. nov. (M.L. gen. n. hall'i.i of Hall [named for Ivan C. Hall, an American bacteriologist].) Obligately anaerobic, gram-positive, nonmotile rods occurring singly and in pairs, occasionally in chains. Cells of the type strain were 0.8 to 1.7 by 4.7 to more than $25.0 \mu \mathrm{m}$ (filaments) in PY-glucose cultures (Fig. 14). The sizes of six strains measured ranged from 0.8 to 2.4 by 4.7 to more than $25.0 \mu \mathrm{m}$. Subterminal and terminal swellings were seen, but the cultures did not survive heating at $70 \mathrm{C}$ for $10 \mathrm{~min}$.

Colonies. After incubation for 5 days in RGCA roll tubes, colonies were 0.5 to $1.0 \mathrm{~mm}$ in diameter and lenticular or "woolly balls." Surface colonies (BHIA streak tubes or anaero- 


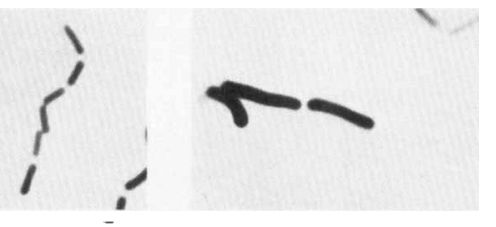

FIG. 14. Eubacterium hallii. Left, cells from $P Y$ broth culture. Right, cells from PY-glucose broth culture. See Fig. 16 for scale.

bic BAP) were 1 to $2 \mathrm{~mm}$ in diameter, circular to slightly irregular, entire to slightly erose, low convex, semi-opaque, white to yellowish, smooth, shiny, and nonhemolytic. No growth occurred on BAP incubated in a candle jar or in an aerobic atmosphere.

Cultural characteristics. There was moderate growth in PY broth. PY-glucose cultures had abundant growth, smooth or ropy sediment with little or no turbidity, and a pH of 4.7 to 5.5 in 5 days. The addition of $0.1 \%$ Tween 80 or $10 \%$ rumen fluid did not affect growth in PY-glucose.

The temperature for optimal growth was 37 C. Most strains grew at $30 \mathrm{C}$, but less well than at $37 \mathrm{C}$. The strains usually did not grow at 25 $\mathrm{C}$ and often did not grow at $45 \mathrm{C}$.

Biochemical reactions. The characteristics for 13 isolates of this species are given in Table 4 . In addition, the type strain and five of five other strains tested produced acid from galactose and reduced neutral red. They did not ferment adonitol, dextrin, glycerol, inulin, or sorbose; did not produce AMC, ammonia, urease, $\mathrm{H}_{2} \mathrm{~S}$ (SIM), lecithinase or lipase (EYA) and did not hydrolyze hippurate or grow in PY-6.5\% NaCl-glucose broth.

Fermentation products. Fermentation products (average milliequivalents per $100 \mathrm{ml}$ of culture) were as follows.

From PY-glucose: Butyric (3.4) and acetic (0.4) acids and butanol, sometimes with small amounts of formic, succinic, or lactic acids. Abundant hydrogen was produced.

From PY: Acetic acid (0.4).

Some strains converted pyruvate to moderate amounts of butyrate and acetate. Lactate and gluconate were not utilized; threonine was not converted to propionate.

$\mathbf{G}+\mathbf{C}$ content of the DNA: $38 \mathrm{~mol} \%$ by $T_{m}$ for the type strain.

Type strain: ATCC 27751 (= VPI B4-27); isolated from human feces.

Production of large amounts of butyric acid and butanol, morphological characteristics of the cells, and carbohydrates fermented help differentiate $E$. hallii from other species with which it might be confused.

\section{New anaerobic species of Lactobacillus}

Characteristics of Lactobacillus rogosae $\mathrm{sp}$. nov. are given in Table 4 and in the following discussion.

(i) Lactobacillus rogosae sp. nov. (M.L. gen. n. ro.go'sae of Rogosa [named for Morrison Rogosa, an American bacteriologist].) Obligately anaerobic, gram-positive, nonsporeforming rods, occurring singly and in pairs and short chains. Cells of the type strain and of four other strains measured were 0.4 to 0.65 by 1.1 to $7.9 \mu \mathrm{m}$ in PY-fructose cultures (Fig. 15). The type strain and most other strains were motile and peritrichous; nonmotile strains without flagella also have been isolated.

Colonies. After incubation for 5 days in RGCA, colonies were 0.5 to $1.0 \mathrm{~mm}$ in diameter, translucent to transparent, lenticular to diffuse, and tan to colorless. Surface colonies on Sweet $\mathrm{E}$ agar (5) streak tubes were $1 \mathrm{~mm}$ in diameter, circular, raised to convex, entire, translucent to opaque, dull, and smooth. Only one of six strains tested grew on BAP incubated anaerobically; none grew on BAP incubated in a candle jar or in an aerobic atmosphere.

Cultural characteristics. There was poor growth in PY broth. PY-fructose cultures had moderate to abundant growth with smooth sediment, usually with turbidity, and a $\mathrm{pH}$ of 4.9 to 5.5 in 5 days. Addition of $0.1 \%$ Tween 80 or $10 \%$ rumen fluid generally did not affect growth in PY-glucose broth.

The temperature for optimal growth was 37 C. Generally there was poorer growth, or no growth, at 30 and $45 \mathrm{C}$.

Biochemical reactions. The characteristics of nine isolates of this species are given in Table 4. In addition, the type and five other strains tested produced a small amount of ammonia in chopped meat cultures and reduced neutral red. They did not produce $\mathrm{H}_{2} \mathrm{~S}$ (SIM) or AMC or hydrolyze hippurate. They did not ferment adonitol, dextrin, glycerol, inulin, or sorbose and often did not grow in PY broth to which these substrates had been added.
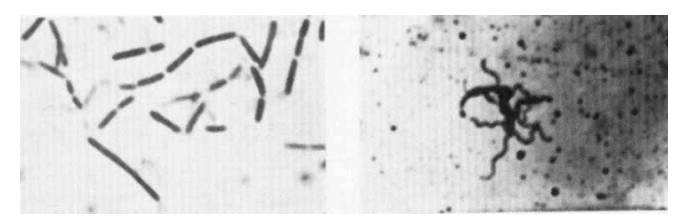

FIG. 15. Lactobacillus rogosae. Left, cells from $P Y$-fructose broth culture. Right, flagella stain, cells from PY-fructose broth culture. See Fig. 16 for scale. 
Fermentation products. Fermentation products (average milliequivalents per $100 \mathrm{ml}$ of culture) were as follows.

From PY-fructose: DL-Lactic (2.3) and acetic (0.9) acids, usually with ethanol and small amounts of succinic or formic acids. No hydrogen was detected.

From PY: Small amounts of acetic acid, usually with traces of lactic or succinic acids, or both.

From PY-pyruvate: Acetate (4.3), formate (2.3), and lactate (0.9), often with a trace of succinate.

Lactate and gluconate were not utilized; threonine was not converted to propionate.

G+C content of the DNA. This was not determined for the type strain because of poor growth in large culture and insufficient harvest of DNA; a value of $59 \mathrm{~mol} \%$ by $T_{m}$ for VPI C36-52 (nonmotile strain) was obtained.

Type strain: ATCC 27753 (= VPI C37-38); isolated from human feces.

Fermentation of fructose with little or no fermentation of other carbohydrates help differentiate $L$. rogosae from other species of lactobacilli.

\section{New species of Clostridium}

Characteristics of Clostridium nexile sp. nov. are given in Table 4 and in the following discussion.

(i) Clostridium nexile sp. nov. (L. adj. nex'.i.le tied together [referring to its chain formation].) Obligately anaerobic, gram-positive, nonmotile coccobacilli to rods, occurring in pairs and chains. Cells of the type strain were 0.8 to 1.6 by 1.3 to $6.3 \mu \mathrm{m}$ in PY-glucose cultures. The sizes of four other strains measured range from 0.8 to 1.6 by 0.8 to $4.7 \mu \mathrm{m}$. The type strain resisted heating at $80 \mathrm{C}$ for 10 min, but no spores were ever seen. Round subterminal (nearly terminal) spores were seen in $E$ broth (5) cultures of strain VPI C35-9 A (Fig. 16), but this culture did not survive heating at $70 \mathrm{C}$ for $10 \mathrm{~min}$. Of five strains carefully checked, three survived heating at 70 $\mathrm{C}$ for $10 \mathrm{~min}$, but no spores were seen; spores were seen in a strain that did not survive, and one similar strain did not survive and no spores were seen.

Colonies. After incubation for 5 days in RGCA, colonies were 0.5 to $1.0 \mathrm{~mm}$ in diameter, $\tan$, lenticular, and translucent to semi-opaque. Surface colonies (anaerobic BAP or BHIA streak tube) were 0.5 to $1.0 \mathrm{~mm}$ in

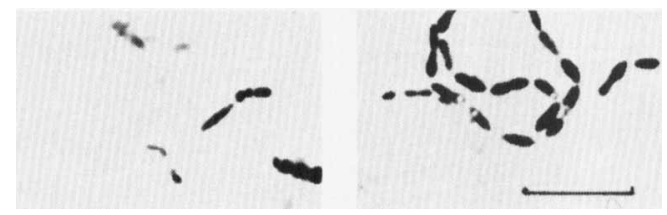

FIG. 16. Clostridium nexile, Left, cells from $P Y$ broth culture. Right, cells from PY-glucose broth culture. Bar represents $10 \mu \mathrm{m}$.

diameter, circular, entire, convex to raised, semi-opaque or with opaque centers and translucent edges, smooth, shiny, white or yellowish, and nonhemolytic.

Cultural characteristics. There was slight to moderate growth in PY broth. PY-glucose cultures had abundant growth with smooth or ropy sediment, sometimes without turbidity, and a $\mathrm{pH}$ of 4.9 to 5.3 in 5 days. Growth was not affected by the addition of $0.1 \%$ Tween 80 or $10 \%$ rumen fluid to PY-glucose broth.

The temperature for optimal growth was 37 C. Strains usually grew well at 30 and $45 \mathrm{C}$ but poorly at $25 \mathrm{C}$.

Biochemical reactions. The characteristics of 11 isolates of this species are given in Table 4. In addition, the type and five other strains tested fermented galactose and reduced neutral red. They did not ferment adonitol, dulcitol, glycerol, or sorbose. They did not produce AMC, urease, ammonia, lecithinase or lipase (EYA), or hydrolyze orotic acid. The type strain produced weak acid from dextrin; the other five strains did not. Inulin was not fermented by the type or by two of five other strains tested. Hippurate was not hydrolyzed by the type and four of five other strains tested. The type strain and two of five other strains tested produced a small amount of $\mathrm{H}_{2} \mathrm{~S}$ (SIM).

Fermentation products. Fermentation products (average milliequivalents per $100 \mathrm{ml}$ of culture) were as follows.

From PY-glucose: Acetic (2.4) and formic (1.4) acids and ethanol, often with trace to moderate amounts of succinic or lactic acids, or both. Abundant hydrogen was produced.

From PY-pyruvate: Acetate (2.6) and ethanol, usually with formate (0.5), occasionally with small amounts of lactate.

From PY: Acetic acid (0.3), sometimes with traces of lactic and succinic acids.

G+C content of the DNA: $40 \mathrm{~mol} \%$ by $T_{m}$ for the type strain and $41 \mathrm{~mol} \%$ for VPI C35-9A.

Type strain: ATCC 27757 (= VPI C48-37); isolated from human feces.

C. nexile differs from Clostridium oroticum, which in some cultures it resembles morpho- 
logically, by not hydrolyzing orotic acid and by not producing acid from arabinose, dulcitol, maltose, and rhamnose.

\section{ACKNOWLEDGMENTS}

This work was supported primarily by Public Health Service grant 14604 from the National Institute of General Medical Sciences and by Public Health Service contract 71-2427 from the National Cancer Institute. We also wish to thank Barbara Francis and John L. Johnson for determinations of the DNA G $+C$ ratios; Thomas O. MacAdoo of the Foreign Language Department of this institution for assistance with nomenclatural terms and derivations; Loretta Albert, Maeve Crowgey, Ann Donnelly, Luba Fabrycky, Ed Hanna, Linda Knight, Carolyn Hubbard, Susan Sieg, Gail Selph, and others of our laboratory who performed work on or for this project; and Elizabeth Cato and Ruth Beyer for help in compilation of the data.

\section{REPRINT REQUESTS}

Address reprint requests to: Lillian V. Holdeman, Anaerobe Laboratory, Virginia Polytechnic Institute and State University, P. O. Box 49, Blacksburg, Va. 24060 .

\section{LITERATURE CITED}

1. Douglas, H. C. 1957. Peptococcus Kluyver and Van Neil, 1936, p. 477. In R. S. Breed, E. D. G. Murray, and N. R. Smith (ed.), Bergey's manual of determinative bacteriology, 7 th ed. Williams and Wilkins Co., Baltimore, Md.

2. Eggerth, A. H. 1935. The gram-positive nonsporebearing anaerobic bacilli of human feces. J. Bacteriol. 30:277-299.

3. Hare, R. 1967. The anaerobic cocci, p. 204-317. In $\mathbf{H}$. P. Waterson (ed.), Recent advances in medical microbiology. Little, Brown \& Co., Boston.

4. Holdeman, L. V., and W. E. C. Moore. 1972. Anaerobic cocci. In L. V. Holdeman and W. E. C.
Moore (ed.), Anaerobe laboratory manual. Anaerobe Laboratory, Virginia Polytechnic Institute and State University, Blacksburg, Va.

5. Holdeman, L. V., and W. E. C. Moore (ed.) 1973. Anaerobe laboratory manual, 2nd ed. Anaerobe Laboratory, Virginia Polytechnic Institute and State University, Blacksburg, Va.

6. Johnson, J. L. 1973. Use of nucleic-acid homologies in the taxonomy of a naerobic bacteria. Int. J. Syst. Bacteriol. 23:308-315.

7. Marmur, J., and P. Doty. 1962. Determination of the base composition of deoxyribonucleic acid from its thermal denaturation temperature. J. Mol. Biol. 5:109-118.

8. Moore, W. E. C., and L. V. Holdeman. 1974. Human fecal flora: the normal flora of 20 Japanese-Hawaiians. Appl. Microbiol. 27:961-979.

9. Prévot, A. R. 1924. Diplococcus constellatus (n. sp.). C. R. Soc. Biol. (Paris) $91: 426-428$.

10. Prévot, A. R. 1925. Les streptocoques anaérobies. Ann. Inst. Pasteur (Paris) 39:415-447.

11. Prévot, A. R. 1933. Etudes de systématique bactérienne. I. Lois generals. II. Cocci anaérobies. Ann. Soc. Nat. 15:23-260.

12. Prévot, A. R. 1938. Études de systématique bactérienne. Ann. Inst. Pasteur (Paris) 60:285-307.

13. Prévot, A. R., A. Turpin, and P. Kaiser. 1967. Les bactéries anaérobies. Dunod, Paris.

14. Rogosa, M. 1971. Peptococcaceae, a new family to include the gram-positive, anaerobic cocci of the genera Peptococcus, Peptostreptococcus, and Ruminococcus. Int. J. Syst. Bacteriol. 21:234-237.

15. Romond, C., R. Sartory, J. Malgras. 1966. Le coefficient de Shapiro-Chargaff des streptocoques anaérobies. Ann. Inst. Pasteur (Paris) 111:110-118.

16. Smith, L. DS. 1957. Peptostreptococcus Kluyver and Van Neil, 1936, p. 540 In R. S. Breed, E. D. G. Murray, and N. R. Smith (ed.), Bergey's manual of determinative bacteriology, 7 th ed. Williams and Wilkins Co., Baltimore, Md.

17. Tunnicliff, R. 1933. Colony formation of Diplococcus rubeolae. J. Infect. Dis. 52-53:39-53.

18. Wachsman, J. T., and H. A. Barker. 1954. Characterization of an orotic acid fermenting bacterium, Zymobacterium oroticum, nov. gen., nov. spec. J. Bacteriol. 68:400-404. 